\title{
Expression of SCUBE2 and BCL2 Predicts Favorable Response in ER $\alpha$ Positive Breast Cancer
} \author{
Mahta Mazaheri, MD, PhD'; Ahmad Kaviani, MD'; Mahdi Rezaee, PhD ${ }^{1,5}$; Keivan Majidzadeh-A, MD, MPH, PhD ${ }^{1 *}$ \\ ${ }^{1}$ Genetics Department, Breast Cancer Research Center, Motamed Cancer Institute, ACECR, Tehran, Iran \\ ${ }^{2}$ Breast Diseases Department, Breast Cancer Research Center, Motamed Cancer Institute, ACECR, Tehran, Iran \\ ${ }^{3}$ Department of Medical Genetics, Shahid Sadoughi University of Medical Sciences, Yazd, Iran \\ ${ }^{4}$ Department of Surgery, Tehran University of Medical Sciences, Tehran, Iran \\ ${ }^{5}$ Seed and plant Certification and Registration Institute, Karaj, Iran
}

Rezvan Esmaeili, PhD'; Samaneh Mohammadi, MSc'; Narges Jafarbeik-Iravani, MSc'; Fatemeh Yadegari, PhD'; Asiieh Olfatbakhsh, MD²;

\begin{abstract}
Background: The study aimed at evaluating steroid biomarker genes $(E R \alpha, P G R, E R \beta)$ and determining the expression level of estrogen-regulated genes (SCUB2 and BCL2) and growth factors receptors (HER2 and IGFR1) in cancer tissue samples obtained from Iranian patients with breast cancer. Moreover, relationships with clinicopathologic aspects of tumor and response to treatment were studied.

Methods: The current study was conducted on 246 breast tissue samples. The expression levels of these genes and their relationships with clinicopathologic aspects and treatment response were evaluated.

Results: Based on immunohistochemistry (IHC) results, $12 \%$ of the ER negative patients expressed ER $\alpha$. Comparing the effects of $E R \alpha$ and coexpression of $B C L 2$ and SCUBE2 on the survival of the patients demonstrated remarkably poorer survival in ER $\alpha$ positive, SCUBE2, and BCL2 negative groups in comparison with other patients, which was statistically significant in the logrank analysis $(P=0.01)$. Evaluation of the effects of coexpression of HER2 and IGFR1 on patients' survival demonstrated a worse survival rate in patients with positive expression of both receptors, which was insignificant.

Conclusion: Many studies suggest that PGR alone is not enough for the functional evaluation of ER $\alpha$. Evaluation of the progesterone receptor expression as well as other genes such as BLC2, SCUBE2, and IGFR1, seems necessary to evaluate functionality.

Keywords: BLC2, ER, IGFR1, Multigene model, SCUBE2

Cite this article as: Esmaeili R, Mohammadi S, Jafarbeik-Iravani N, Yadegari F, Olfatbakhsh A, Mazaheri M, et al. Expression of SCUBE2 and BCL2 predicts favorable response in ER positive breast cancer. Arch Iran Med. 2021;24(3):209-217. doi: 10.34172/ aim.2021.32.
\end{abstract}

Received: May 31, 2020, Accepted: October 19, 2020, ePublished: March 1, 2021

\section{Introduction}

Today, cancer studies are focused on finding diagnostic, predictive, and prognostic biomarkers. These biomarkers are commonly assessed in tumor tissues by categorizing patients into different subgroups leading to the selection of effective therapeutic methods. Since breast cancer (BC) is a heterogeneous disease, finding such biomarkers is of great importance to personalize the treatment.

Most of the clinically approved biomarkers are assessed using immunohistochemistry (IHC). Nevertheless, some recently developed cancer genetic panels such as Oncotype DX employ quantitative real-time polymerase chain reaction (qRT-PCR) to assess biomarkers. ${ }^{1}$ Several studies reported some practical biomarkers to predict the efficacy of different therapeutic approaches for BC such as hormone therapy, targeted therapy, and chemotherapy. ${ }^{2-5}$ However, none of them are approved for clinical practice yet.

In about $70 \%$ of patients with $\mathrm{BC}$, estrogen receptor alpha $(E R \alpha)$ is expressed in the early tumor, which indicates that tumor cells growth is hormone-dependent and such patients can benefit from endocrine treatment; moreover, tamoxifen is the standard choice in most of the patients with $E R \alpha^{+}$patients. Nevertheless, the prognosis of $\mathrm{ER} \alpha^{+}$cases is different, and some of them develop resistance against treatment after the therapeutic course, while the mechanism of this resistance is not entirely understood. ${ }^{6}$ Expression of progesterone receptor $(P G R)$ is another factor; in other words, $P G R^{+}$indicates that the $E R$ signaling pathway is functional in such patients. $P G R^{+}$in tissue samples is a positive predictive factor and indicates the functionality of the $E R \alpha^{+}$pathway and the patient may gain maximum advantage from blocking the pathway. ${ }^{7,8}$ Most of the studies recommend that $P G R$ alone is not enough for the functionality of $E R \alpha{ }^{9}$ According to a variety of responses to therapeutic methods in $E R \alpha^{+} / P G R^{+}$ patients and sometimes lack of response to treatment in the early stages, the expression of signal peptides, CUB

*Corresponding Author: Keivan Majidzadeh-A, MD, MPH, PhD; Genetics Department, Breast Cancer Research Center, Motamed Cancer Institute, ACECR, No 146, South Gandhi Ave, Vanak Sq., Tehran, Iran. Tel: +98-2188796003; Fax: +9821-88796208; Email: kmajidzadeh@acecr.ac.ir 
domain, and EGF such as domains containing 2 (SCUB2) and B-cell leukemia/lymphoma 2 (BCL2) as well as PGR is of great importance. ${ }^{10,11}$ These genes are suggested as estrogen-regulated genes. ${ }^{12,13}$ Some studies suggest measuring these markers to predict hormone therapy.

In addition to hormone therapy, the expression of biomarkers plays a significant role in responding to other therapeutic agents such as chemotherapy and targeted cancer therapy. For example, it was observed that in addition to $H E R 2$, blocking the expression of $E R$ and insulin-like growth factor receptor-1 (IGFR1) influences response to treatment with herceptin. ${ }^{14}$ It was also observed that lower expression of IGFRI after chemotherapy is associated with better response to treatment in patients undergoing ACT (adriamycin, cyclophosphamide, and taxotere) chemotherapy. ${ }^{15}$ It is noteworthy that higher expression of IGFR1 exacerbates response to chemotherapy and higher activity of IGFR1 protein induces resistance to radiotherapy and chemotherapy. ${ }^{16}$

In recent years, the expression of $E R \beta$, the second identified estrogen receptor, is evaluated in different studies and the results are rather controversial. ${ }^{17-19}$ Tumors with higher levels of $E R \beta$ expression have a lower risk of an event such as recurrence or metastasis compared with tumors with lower expression levels in patients undergoing chemotherapy. ${ }^{20}$

The current study aimed at evaluating steroid biomarker genes (ER $\alpha, P G R, E R \beta)$ and determining the expression level of estrogen-regulated genes (SCUB2 and BCL2) and growth factor receptors (HER2 and IGFR1) in cancer tissue samples obtained from Iranian patients with BC using realtime PCR. Also, their relationships with clinicopathologic aspects of tumor and response to treatment were evaluated.

\section{Materials and Methods}

Tissue and Sample

The current study was conducted on 246 breast tissue samples including 123 tumors and 123 normal adjacent tissues. Sample size was calculated using an online web tool with $95 \%$ confidence level, $80 \%$ margin of error and $10 \%$ population proportion. ${ }^{21,22}$ The sample size was calculated at 62 for each group. Due to the possibility of sample attrition, 123 samples were considered in each group. Tissue samples along with clinicopathologic data were obtained from the Breast Cancer Research Center Biobank (BCRC-BB), Iran. According to the protocols followed by BCRC-BB, immediately after excisional biopsy or surgery, sample tissues were snap-frozen in liquid nitrogen and stored at $-70^{\circ} \mathrm{C} .^{23}$

Primers and TaqMan probes were designed by Gene Runner software version 3.0 .5 for $E R \alpha, P G R, E R \beta$, SCUBE2, BCL2, HER2, and IGFR1. The list of primers and probes are available upon request. $A C T B$ and TFRC were used as housekeeping genes. ${ }^{24}$
RNA Extraction and cDNA Synthesis and Gene Expression Assay

RNA extraction was performed using $820 \mathrm{mg}$ of the breast tumor and normal adjacent tissue by Rnx-Plus (Cinagen, Iran) as previously explained. ${ }^{24}$ The quality and quantity of the extracted RNA were measured by gel electrophoresis and spectrophotometry, respectively. The cDNA synthesis was performed using the cDNA synthesis Kit (Qiagen, Germany) according to the manufacturer's protocol. RealTime PCR was conducted using SYBR Green Master mix (Takara, Japan) and ABI 7500 version 2.0.6. Normal adjacent tissue was used as control.

\section{Data Analysis}

Gene expression was analyzed using the 2- $\Delta \Delta \mathrm{CT}$ method. Gene expression amounts $>2$ were considered as upregulation. Data were analyzed using SPSS version 19.0 (SPSS, Inc., Chicago, IL, USA). The student $t$ test was used to compare $\triangle \mathrm{CT}$ between tumor and normal adjacent tissue. The frequency of genes expression was presented in total samples and also in ER- and ER+ positive patients separately (ER protein expression production based on IHC results). Age and follow-up time were presented as median/IQR and median/range respectively. Clinicopathologic data were presented as categorical data with frequencies and percentages. Shapiro Wilk's and Levene tests and probability plots were used to evaluate the normal distribution of the variables and the homogeneity of variances, respectively. One-way analysis of variance (ANOVA) was employed to conduct the comparisons among the three groups.

The chi-square or the Fisher exact tests were used to determine the significance of differences between up- or downregulated gene expression and clinicopathologic variables. The correlation between gene expressions and clinicopathologic data was evaluated by following the Shapiro-Wilk's method for normality tests and Pearson's for correlation tests using the Pearson correlation test. The Kaplan-Meier analysis with log-rank tests was performed to calculate the cumulative survival proportion for disease free survival (DFS) based on the gene expression level. A Cox proportional hazards model was applied to investigate the univariate hazard ratio. Date of surgery was assumed as time zero. For multivariate analysis, variables with $P$ $<0.2$ in univariate analysis were included. $P<0.05$ was considered to specify a statistically significant result.

\section{Results}

Patients

Demographic and clinicopathological data of the patients including age at diagnosis, IHC results of estrogen, progesterone and HER2 receptors, stage, grade, lymph nodes, and tumor size are summarized in Table 1 . The number of triple negative subtypes in comparison with other subtypes is also included. The median age of the 
Table 1. Demographic and Clinicopathologic Data of the Patients $(n=125)$

\begin{tabular}{|c|c|}
\hline Age (median/IQR) (y) & $48(14.75)$ \\
\hline IQR (Q3, Q1) & $(54.75,40)$ \\
\hline Follow-up (median/range) (mon) & $48.5(1-65)$ \\
\hline \multicolumn{2}{|l|}{ ER (9 missing), No. (\%) } \\
\hline Negative & $44(37.9)$ \\
\hline Positive & $72(62.1)$ \\
\hline \multicolumn{2}{|l|}{$P R$ (10 missing), No. (\%) } \\
\hline Negative & $53(46.1)$ \\
\hline Positive & $62(53.9)$ \\
\hline \multicolumn{2}{|l|}{ HER2/neu (11 missing), No. (\%) } \\
\hline Negative & $81(58.0)$ \\
\hline Positive & $33(23.7)$ \\
\hline \multicolumn{2}{|l|}{ Grade (13 missing), No. (\%) } \\
\hline G1 & $12(10.6)$ \\
\hline G2 & $72(63.7)$ \\
\hline G3 & $29(25.7)$ \\
\hline \multicolumn{2}{|l|}{ Patient status (7 missing), No. (\%) } \\
\hline Healthy survival & $92(78.0)$ \\
\hline With events & $26(22.0)$ \\
\hline \multicolumn{2}{|l|}{ Stage(22 missing), No. (\%) } \\
\hline 1 & $9(8.7)$ \\
\hline II & $47(45.2)$ \\
\hline III & $35(33.7)$ \\
\hline IV & $13(12.5)$ \\
\hline \multicolumn{2}{|l|}{ Tumor size (13 missing), No. (\%) } \\
\hline$<2 \mathrm{~cm}$ & $30(29.8)$ \\
\hline $2-5 \mathrm{~cm}$ & $65(58.0)$ \\
\hline$>5$ & $17(15.2)$ \\
\hline \multicolumn{2}{|l|}{ Lymph node (14 missing), No. (\%) } \\
\hline No & $32(28.8)$ \\
\hline $1-3$ & $33(29.7)$ \\
\hline $4-9$ & $31(27.9)$ \\
\hline$>9$ & $15(13.5)$ \\
\hline \multicolumn{2}{|l|}{ Subtype, No. (\%) } \\
\hline Triple negative & $22(19.4)$ \\
\hline Other & $91(80.6)$ \\
\hline
\end{tabular}

$\mathrm{IQR}$, Interquartile range.

patients was 48 years (range 29-87), and median followup was 48.5 months (range 1-65).

\section{Gene Expression}

The frequencies of upregulated, downregulated, and no changes in gene expressions are summarized in Table 2. It was observed that $E R \alpha$ and $E R \beta$ were also expressed in ER patients (based on IHC results). Twelve percent of ER patients expressed ER . Also, the expression of this gene was absent in $5 \%$ of $\mathrm{ER}^{+}$patients, but $E R \beta$ expression was almost the same in $\mathrm{ER}^{+}$and $\mathrm{ER}^{-}$groups. This pattern was observed for PGR, SCUBE2, and BCL2 expression as estrogen related genes. Some $\mathrm{ER}^{+}$patients lacked the expression of these genes, while some ERpatients expressed the abovementioned genes. There was a significant difference between tumor and matched normal tissue samples in the expression of BCL2, ER,$H E R 2$, $P G R$, and SCUBE2. P values are 0.0001, 0.0001, 0.005, 0.0001 , and 0.0001 , respectively.

The ANOVA analysis showed that patients with larger tumor sizes expressed higher HER2 $(P=0.028)$ and lower ER $\beta$ levels $(P=0.029)$. Moreover, patients above 50 years expressed higher HER2 $(P=0.05)$ and lower ER $(P=$ $0.047)$. It was also observed that tumors with lower levels of $E R \alpha$ expression had higher grades $(P=0.032)$ (data not shown).

Correlation of Gene Expressions and Clinicopathologic Data

As shown in Table 3, a significant negative correlation was observed between ER $\beta$ expression and tumor stage $(P=$ 0.006). Moreover, upregulation of HER2 was correlated with higher stage and tumor size $(P=0.028, P=0.041)$.

The correlations between different genes are shown in Table 4. There was a significant correlation between ER $\alpha$ and PGR $(P<0.001)$ and SCUBE2 $(P<0.001)$, and SCUBE2 and IGFR1 $(P<0.001)$. There were also significant negative correlations between $E R \alpha$ and IGFRI $(P<0.001), E R \beta$ and HER2 $(P<0.001)$, and PGR and IGFR1 $(P<0.001)$. The two latter correlations were strong. Other correlations were not significant. Chisquare analysis showed that upregulation of IGFRI was associated with triple negative subtype $(P=0.01)$ (data not shown). Analysis of $B C l 2, S C U B E 2$, and $E R \beta$ showed no significant association with the type of tumor.

Survival Analysis and Prognostic Significance of Gene Expressions

Association between the selected gene expressions and patient survival was evaluated using the Kaplan-Meier analysis with a log-rank test for DFS. The median followup duration was 48.5 months (95\% CI: 1-65 months). According to this analysis, gene expression status had no significant impact on survival of patients. Prognostic values of all gene expressions were investigated in the univariate and multivariate analyses of DFS. Although upregulation of $E R \alpha, H E R 2$, and $P G R$ showed negative effects on survival and upregulation of BCL2, IGFR1, $S C U B E 2$, and $E R \beta$ had positive effects on survival, the results were only significant for $E R \alpha$. Multivariate analysis was not significant for the selected biomarkers (Table 5). Comparison of the effects of $E R \alpha$ and coexpression of BCL2 and SCUBE2 on patients' survival demonstrated a remarkably poorer survival rate in $E R \alpha^{+}, S C U B E 2$, and $B C L 2^{-}$groups in comparison with other patients, which was statistically significant in the log-rank analysis $(P=$ 0.01). Comparison of the effects of HER2 and IGFR1 coexpression on patients' survival demonstrated a worse survival rate in patients with positive expression for both 
Table 2. Frequency of Gene Expression in $\mathrm{ER}^{-}$and $\mathrm{ER}^{+}$Patients

\begin{tabular}{|c|c|c|c|c|c|c|}
\hline & $\mathbf{N}^{*}$ & Percent & N (ER-Patients) & Percent & N (ER+ Patients) & Percent \\
\hline \multicolumn{7}{|l|}{$E R \alpha$} \\
\hline Down & 52 & 41.6 & 24 & 54.5 & 25 & 35.2 \\
\hline No change & 16 & 12.8 & 9 & 20.5 & 5 & 7 \\
\hline Up & 57 & 45.6 & 11 & 22.7 & 41 & 57.7 \\
\hline \multicolumn{7}{|l|}{$E R \beta$} \\
\hline Down & 33 & 26.4 & 12 & 27.3 & 18 & 25.4 \\
\hline No change & 8 & 6.4 & 2 & 27.34 .5 & 5 & 7 \\
\hline Up & 84 & 67.2 & 30 & 68.2 & 48 & 67.6 \\
\hline \multicolumn{7}{|l|}{$P G R$} \\
\hline Down & 66 & 52.8 & 26 & 59.1 & 35 & 49.3 \\
\hline No change & 17 & 13.6 & 3 & 6.8 & 13 & 18.3 \\
\hline Up & 42 & 33.6 & 15 & 34.1 & 23 & 32.4 \\
\hline \multicolumn{7}{|l|}{ SCUBE2 } \\
\hline Down & 86 & 68.8 & 26 & 59.1 & 52 & 73.2 \\
\hline No change & 14 & 11.2 & 7 & 15.9 & 7 & 9.9 \\
\hline Up & 25 & 20 & 11 & 25 & 12 & 16.9 \\
\hline \multicolumn{7}{|l|}{ HER2 } \\
\hline Down & 94 & 75.2 & 32 & 72.7 & 53 & 74.6 \\
\hline No change & 9 & 7.2 & 1 & 2.3 & 7 & 9.9 \\
\hline Up & 22 & 17.6 & 11 & 25 & 11 & 15.5 \\
\hline \multicolumn{7}{|l|}{ IGFR } \\
\hline Down & 60 & 48 & 18 & 40.9 & 37 & 52.1 \\
\hline No change & 14 & 11.2 & 177 & 15.9 & 6 & 8.5 \\
\hline Up & 51 & 40.8 & 19 & 43.2 & 28 & 39.4 \\
\hline \multicolumn{7}{|l|}{$B C L 2$} \\
\hline Down & 60 & 48 & 25 & 56.8 & 31 & 43.7 \\
\hline No change & 26 & 20.8 & 9 & 20.5 & 14 & 19.7 \\
\hline Up & 39 & 31.2 & 10 & 22.7 & 26 & 36.6 \\
\hline
\end{tabular}

$* \mathrm{~N}, \mathrm{~N}($ ER- Patients $)+\mathrm{N}($ ER+ Patients $)+$ missing.

Table 3. Pearson Correlation Coefficient for Different Gene Expressions and Clinicopathologic Data

\begin{tabular}{|c|c|c|c|c|c|c|}
\hline Gene & Stage & Grade & LN & T Size & Status & Age at Diagnosis \\
\hline$E R a$ & -0.048 & -0.086 & 0.047 & -0.078 & 0.143 & -0.04 \\
\hline$E R b$ & $-0.271 * *$ & 0.048 & -0.183 & -0.168 & -0.065 & -0.15 \\
\hline BCLJH2 & -0.041 & 0.026 & -0.029 & 0.018 & -0.10 & 0.06 \\
\hline HER2 & $0.220^{*}$ & -0.023 & 0.177 & $0.193^{*}$ & 0.037 & 0.21 \\
\hline PGR & 0.084 & -0.046 & -0.066 & 0.092 & 0.064 & $-0.16^{*}$ \\
\hline SUBE2 & -0.066 & 0.121 & 0.001 & -0.065 & -0.067 & -0.063 \\
\hline IGFR1 & -0.084 & 0.049 & 0.48 & -0.083 & -0.023 & 0.05 \\
\hline
\end{tabular}

$* P$ value $\leq 0.05, * * P$ value $\leq 0.01$.

Table 4. The Correlations between Different Gene Expressions

\begin{tabular}{|c|c|c|c|c|c|c|}
\hline & ERaCAT & ERbCAT & PGRCAT & SCUBE2CAT & HER2CAT & IGFRCAT \\
\hline ERaCAT & 1.000 & & & & & \\
\hline ERbCAT & 0.032 & 1.000 & & & & \\
\hline PGRCAT & $0.315^{* *}$ & 0.164 & 1.000 & & & \\
\hline SCUBE2CAT & $-0.469^{* *}$ & 0.128 & $-0.201^{*}$ & 1.000 & & \\
\hline HER2CAT & -0.099 & $-0.882^{* *}$ & -0.174 & -0.089 & 1.000 & \\
\hline IGFRCAT & $-0.388^{* *}$ & -0.127 & $-0.902 * *$ & $0.311^{* *}$ & 0.145 & 1.000 \\
\hline
\end{tabular}

$* P$ value $\leq 0.05, * * P$ value $\leq 0.01$ 
receptors, but the result was not significant $(P=0.1)$ (Figure 1). Coexpression of ER 3 and IGFR1 and other combinations of gene expression was not significant.

\section{Discussion}

In the current study, the expression of $E R \alpha, P G R, E R \beta$, SCUBE2, BCL2, HER2, and IGFR1 genes was investigated using real-time PCR. The findings demonstrated the significant effect of coexpression of Bcl2 and SCUBE2 on the survival of patients with $E R \alpha$ overexpression. To the best of the authors' knowledge, the effect of coexpression of these two genes was reported only in the recurrence score calculation in Oncotype DX along with 18 other genes, which calculated the risk of distant metastasis in

Table 5. Univariate and Multivariate Analysis of Prognostic Impact of Both Clinicopathologic Parameters on Disease Free Survival

\begin{tabular}{|c|c|c|c|c|c|c|}
\hline \multirow{2}{*}{ Overall Survival } & \multicolumn{3}{|c|}{ Univariate } & \multicolumn{3}{|c|}{ Multivariate } \\
\hline & Hazard Ratio & $95 \% \mathrm{Cl}$ & $P$ Value & Hazard Ratio & $95 \% \mathrm{Cl}$ & $P$ Value \\
\hline \multicolumn{7}{|l|}{$E R \alpha$} \\
\hline No and Down & 1 & & & 1 & & \\
\hline Up & 2.90 & $0.91-9.2$ & 0.07 & 2.27 & $0.685-7.583$ & 0.180 \\
\hline \multicolumn{7}{|l|}{$E R \beta$} \\
\hline No and Down & 1 & & & 1 & & \\
\hline Up & 0.54 & $0.22-2.68$ & 0.2 & 0.58 & $0.203-1.686$ & 0.321 \\
\hline \multicolumn{7}{|l|}{ Her2 } \\
\hline No and down & 1 & & & & & \\
\hline Up & 1.40 & $0.44-4.5$ & 0.54 & & & \\
\hline \multicolumn{7}{|l|}{$P G R$} \\
\hline No and down & 1 & & & & & \\
\hline Up & 1.80 & $0.65-5.3$ & 0.23 & & & \\
\hline \multicolumn{7}{|l|}{ SCUBE2 } \\
\hline No and down & 1 & & & & & \\
\hline Up & 0.89 & $0.20-4.01$ & 0.88 & & & \\
\hline \multicolumn{7}{|l|}{ IGFR1 } \\
\hline No and down & 1 & & & & & \\
\hline Up & 0.69 & $0.23-2.08$ & 0.52 & & & \\
\hline \multicolumn{7}{|l|}{$B C L 2$} \\
\hline No and down & 1 & & & & & \\
\hline Up & 0.74 & $0.23-2.3$ & 0.62 & & & \\
\hline \multicolumn{7}{|l|}{ ER IHC } \\
\hline Negative & 1 & & & & & \\
\hline Positive & 0.70 & $0.25-2.2$ & 0.6 & & & \\
\hline \multicolumn{7}{|l|}{ PR IHC } \\
\hline Negative & 1 & & & & & \\
\hline Positive & 0.80 & $0.27-2.4$ & 0.7 & & & \\
\hline \multicolumn{7}{|l|}{ HER2 IHC } \\
\hline Negative & 1 & & & & & \\
\hline Positive & 1.20 & $0.38-4.1$ & 0.69 & & & \\
\hline \multicolumn{7}{|l|}{ Stage } \\
\hline I and II & 1 & & & 1 & & \\
\hline II and IV & 3.20 & $0.82-12.4$ & 0.09 & 1.05 & $0.418-2.658$ & 0.911 \\
\hline \multicolumn{7}{|l|}{ Grade } \\
\hline I and II & 1 & & & & & \\
\hline III & 1.70 & $0.54-5.8$ & 0.3 & & & \\
\hline \multicolumn{7}{|l|}{ Tumor Size } \\
\hline I and II & 1 & & & 1 & & \\
\hline III and IV & 2.60 & $0.8-8.9$ & 0.10 & 2.49 & $0.692-8.996$ & 0.162 \\
\hline \multicolumn{7}{|l|}{ LN } \\
\hline No and I-III & 1 & & & 1 & & \\
\hline IV-IX and $>I X$ & 2.87 & $0.86-9.56$ & 0.08 & 1.46 & $0.413-5.195$ & 0.554 \\
\hline \multicolumn{7}{|l|}{ LN } \\
\hline Negative & 1 & & & & & \\
\hline Positive & 5.10 & $0.66-40.1$ & 0.1 & & & \\
\hline ER IHC & & & & & & \\
\hline Negative & 1 & & & & & \\
\hline Positive & 1.30 & $0.44-3.97$ & 0.6 & & & \\
\hline PR IHC & & & & & & \\
\hline Negative & 1 & & & & & \\
\hline Positive & 1.20 & $0.40-3.6$ & 0.7 & & & \\
\hline HER2 IHC & & & & & & \\
\hline Negative & 1 & & & & & \\
\hline Positive & 0.80 & $0.24-2.56$ & 0.7 & & & \\
\hline
\end{tabular}

$\mathrm{Cl}$, confidence interval 

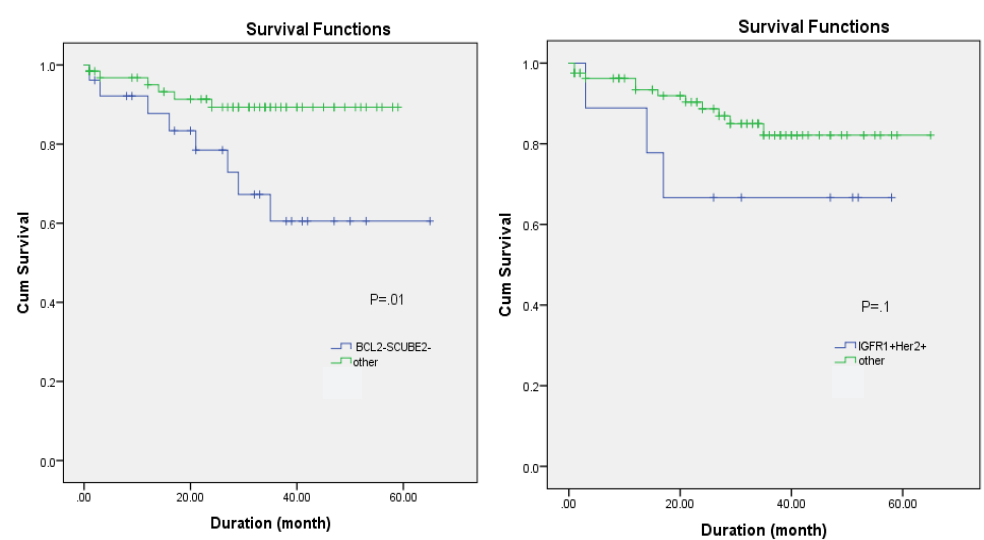

Figure 1. The Kaplan-Meier Plot. The Kaplan Meier plot of patient survival stratified by coexpression of BCl2- SCUBE2 (right) and IGFR1-HER2 (left) in ERa+patients; vertical marks show censored patients. The censoring was due to missing data of the patients' follow-up (0.2 in BCI2- SCUBE2 and 0.06 in IGFR1HER2). Censoring means the total survival duration for that patient cannot be accurately determined. Most of the time, it occurs when participants are either excluded or refuse to participate in the study.

patients with stage I and II. ${ }^{1}$ Moreover, a negative effect of coexpression of IGFR1 and HER2 on patients' survival was observed. Other studies show that blocking IGFR1 is helpful for response to herceptin. ${ }^{14}$ Moreover, patients with decreased expression of IGFRI had fewer events in chemotherapy. ${ }^{15}$ Furthermore, increased expression of this protein had a negative impact on resistance to chemo- and radiotherapy. ${ }^{16,25}$ The current study did not investigate the effects of gene expression on different treatment regimens due to unavailability of this data. The results of the current study showed that upregulation of ER,$H E R 2$, and PGR had negative impacts on survival. Also, the effect of $B C L 2$, IGFR1, SCUBE2, and ER $\beta$ upregulation on survival was investigated. However, the results were positively significant for $E R \alpha$.

The prognostic effect of ER,$P G R$, and HER2 gene expression was in accordance with the effect of ER, PR, and HER2 protein by IHC. But there was no correlation between IHC and real-time PCR results of these biomarkers. It should be noted that recent studies have shown different correlations between RT-qPCR and IHC for ER. So, this discordance could be attributed to several factors, as follows. There is a lot of variation in IHC methodology. These wide variations consist of the cold ischemia time which is related to tissue processing, scoring and annotation system and using differences antibody clones, ${ }^{26-28}$ all of which are different between labs. Moreover, the lack of a proper cutoff set for IHC as a semi-quantitative technique with different scoring methodology can cause this disparity. ${ }^{29}$ The IHC technique targets ER protein. However, RT-qPCR evaluates ER gene expression at the RNA level. Therefore, post-translational modification of the ER gene may be responsible for this discrepancy. Tumor dissection is necessary for RT-qPCR assay. Sometimes, incorrect tumor dissection can lead to diverse results, indicating the inclusion of some parts of normal tissue which contaminates the sample. ${ }^{29}$ It should be mentioned that in the current study, tumor dissection was performed only on the tumor part. In the Oncotype Dx test which evaluates the ten-year risk of recurrence in breast cancer, the real-time PCR assay is used for detecting the level of hormone receptors as well as HER2 which shows mRNA expression would be a good choice for diagnostic tests.

The results of the correlation between gene expression and clinicopathologic data of the patients were in concordance or disconcordance with some studies, which will be discussed.

According to previous studies, IGFR1 protein binds to the high-affinity insulin-like growth factor. This receptor has tyrosine activity and is overexpressed in many malignant tissues and acts as an anti-apoptosis factor, which increases the survival rate of cancer cells. In the current study, higher IGF1R expression was a favorable prognostic factor; its expression also had a positive correlation with $S C U B E 2$ expression and a negative correlation with $E R \alpha$ and $E R \beta$ expressions. The results of similar studies are in agreement with those of the current study, although some are inconsistent. LaTonia et al indicated a correlation between increased IGF1R expression and higher grades of the tumor, shorter DFS, and poor prognosis. ${ }^{30}$ Some other studies also reported a correlation between the expression and activity of IGFR1 with disease progression, increased resistance to radiotherapy, and poor prognosis. ${ }^{31,32}$ Higher IGFR1 expression in tumors $>2 \mathrm{~cm}$, and grade II or III was also reported by Browne et al. ${ }^{33}$ A study by Yerushalmi et al showed that the expression of IGFR1 was associated with lower tumor grades, ER expression, and lack of $H E R 2$ expression. Expression of $I G F 1 R$ was associated with good prognostic factors such as older age at diagnosis, lower grades, negative HER2, and higher levels of P27. ${ }^{34}$ In contrast, a study on 60 patients with $\mathrm{BC}$ showed a significant relationship between the increased IGF1R expression and higher tumor grades. They suggested that 
the overexpression of IGFR1 was associated with invasive behavior of tumor cells, but indicated no relationship between IGF1R and stage of the disease or lymph node metastasis. It was also revealed that IGF1R expression might cause angiogenesis by vascular endothelial growth factor, and consequently, metastasis in BC cases. ${ }^{35}$ Nevertheless, some similar studies indicated no association between the expression of IGF1R and clinicopathological features of the tumor; in a study on 210 paraffinembedded early BC tumors, similar to the current study, no relationship was observed between IGF1R expression and clinicopathological features of the disease such as age at incidence, tumor size, lymph nodes status, and hormone receptors. ${ }^{36}$ However, in a study by Al Sarakbi et al, a relationship was observed between the mRNA level of IGF1R and that of lymph nodes. ${ }^{37}$ In a study on nonsmall cell lung cancer cases, increased IGFR1 expression was associated with larger tumor sizes. ${ }^{38}$

The SCUBE2 protein belongs to the SCUBE protein family and is a tumor-inhibitory factor. Expression of SCUBE2 protein has been observed in different tissue such as breast ducts epithelium. ${ }^{39}$ Although the role of this protein is not perfectly identified in healthy cells, its expression is observed in early BC tumors, and better prognosis is reported in patients expressing SCUBE2, compared with the ones who do not express it. ${ }^{11}$ The SCUBE2 protein inhibits tumor growth through the bone morphogenic pathway and beta-catenin signaling pathway. ${ }^{39}$ In the current study, a negative correlation was observed between the expression of ER and PGR with SCUBE2 and also a negative correlation with the expression of $E R \alpha$ and $P G R$ with IGFR1. Also, a significant correlation was observed between the increased expression of this gene and better prognosis in patients with BC. A study by Skrzypczak et al showed that the expression of this gene was reduced in cases with endometrial cancer of higher grades. It is noteworthy that the expression of this gene showed a positive correlation with the expression of $P G R$ and ER. Another study also indicated lower recurrence and better survival rates in patients with colorectal cancer and higher expression levels of these genes; on the other hand, decreased expression of SCUBE2 was associated with progression and prognosis in such patients. ${ }^{40}$

ER $\beta$ belongs to the estrogen receptors family and it is present in nucleus, cytoplasm, and mitochondria. By binding a ligand to $\mathrm{ER} \beta$, it forms homo- and heterodimers, which activate transcription from specific sequences of DNA. Some isoforms of this receptor inhibit the activity of other members of the estrogen receptors family. ${ }^{41}$ In the current study, $E R \beta$ gene showed lower expression levels in tumors with a greater size. Also, patients aged above 50 years had lower ER $\beta$ and higher HER2 expression levels. In a study by Sapino et al on BC using IHC and real-time PCR techniques, the mean age of ER $\beta$ + patients was lower than those with ER $\beta$-, which is in concordance with the findings of the current study. ${ }^{42}$ Miyoshi et al reported that the $E R \beta$ expression was associated with tumors smaller than $2 \mathrm{~cm}$ and higher grades. ${ }^{43}$ The first result is in concordance with the findings of the current study. Another study showed that smaller size tumors and higher overall survival (OS) were associated with lack of $E R \beta$ expression. ${ }^{44}$ In a study on ovarian cancer, $E R \beta$ expression was associated with metastasis to lymph nodes. By evaluating 508 tumor samples, no significant association was observed between $E R \beta$ expression and clinicopathological features. ${ }^{45}$

In conclusion, many studies today suggest that PGR alone is not enough for the functional evaluation of Er $\alpha,{ }^{21}$ based on the variety of responses to treatment in $\mathrm{ER}^{+} / \mathrm{PgR}^{+}$patients and even lack of response to different treatments in the early stages. Evaluation of the progesterone receptor expression as well as other genes such as BLC2 and SCUBE2, IGFR1 (using the multigene model), seems necessary to evaluate the functionality of $\mathrm{ER} \alpha \cdot{ }^{15,22}$

\section{Authors' Contribution}

RE designed the project, was responsible for data analysis and writing the manuscript. SM, NJ, and MR performed the experiments. $\mathrm{AK}$ and $\mathrm{AO}$ were in charge with clinical data. KM conceived and designed the project and critically reviewed data analysis and the manuscript. All authors read and approved the final manuscript.

\section{Conflict of Interest Disclosures}

None declared.

\section{Ethical Statement}

The project was approved by the Ethics Committee of the Breast Cancer Research Center (BCRC). All procedures performed in studies involving human participants were in accordance with the ethical standards of the institutional committee and with the 1964 Helsinki declaration and its later amendments or comparable ethical standards.

\section{Funding}

This study was funded by ACECR (Academic Center for Education, Culture and Research) and grant number is 1828-11.

\section{Acknowledgements}

The authors would like to acknowledge the ACECR for financial support.

\section{References}

1. Paik S, Shak S, Tang G, Kim C, Baker J, Cronin M, et al. A multigene assay to predict recurrence of tamoxifen-treated, node-negative breast cancer. N Engl J Med. 2004;351(27):281726. doi: 10.1056/NEJMoa041588.

2. Guler EN. Gene expression profiling in breast cancer and its effect on therapy selection in early-stage breast cancer. Eur J Breast Health. 2017;13(4):168-174. doi: 10.5152/ ejbh.2017.3636.

3. Li P, Feng C, Chen H, Jiang Y, Cao F, Liu J, et al. Elevated CRB3 expression suppresses breast cancer stemness by inhibiting beta-catenin signalling to restore tamoxifen sensitivity. J Cell Mol Med. 2018;22(7):3423-3433. doi: 10.1111/jcmm.13619.

4. Risi E, GrilliA, Migliaccio I, Biagioni C, McCartneyA, Guarducci $\mathrm{C}$, et al. A gene expression signature of Retinoblastoma lossof-function predicts resistance to neoadjuvant chemotherapy in ER-positive/HER2-positive breast cancer patients. Breast Cancer Res Treat. 2018;170(2):329-41. doi: 10.1007/s10549018-4766-2. 
5. Xu L, Che X, Wu Y, Song N, Shi S, Wang S, et al. SIRT5 as a biomarker for response to anthracycline-taxane-based neoadjuvant chemotherapy in triple-negative breast cancer. Oncol Rep. 2018;39(5):2315-23. doi: 10.3892/or.2018.6319.

6. Ali S, Rasool M, Chaoudhry H, P NP, Jha P, Hafiz A, et al. Molecular mechanisms and mode of tamoxifen resistance in breast cancer. Bioinformation. 2016;12(3):135-9. doi: 10.6026/97320630012135.

7. Cui X, Schiff R, Arpino G, Osborne CK, Lee AV. Biology of progesterone receptor loss in breast cancer and its implications for endocrine therapy. J Clin Oncol. 2005;23(30):7721-35. doi: 10.1200/JCO.2005.09.004.

8. Henriksen KL, Rasmussen BB, Lykkesfeldt AE, Moller S, Ejlertsen B, Mouridsen HT. An ER activity profile including $\mathrm{ER}, \mathrm{PR}, \mathrm{BCl}-2$ and IGF-IR may have potential as selection criterion for letrozole or tamoxifen treatment of patients with advanced breast cancer. Acta Oncol. 2009;48(4):522-31. doi: 10.1080/02841860802676383

9. Skliris GP, Leygue E, Curtis-Snell L, Watson PH, Murphy LC. Expression of oestrogen receptor-beta in oestrogen receptor-alpha negative human breast tumours. $\mathrm{Br} \mathrm{J}$ Cancer. 2006;95(5):616-26. doi: 10.1038/sj.bjc.6603295.

10. Cheng CJ, Lin YC, Tsai MT, Chen CS, Hsieh MC, Chen CL, et al. SCUBE2 suppresses breast tumor cell proliferation and confers a favorable prognosis in invasive breast cancer. Cancer Res. 2009;69(8):3634-41. doi: 10.1158/0008-5472.CAN-083615.

11. Lin YC, Lee YC, Li LH, Cheng CJ, Yang RB. Tumor suppressor SCUBE2 inhibits breast-cancer cell migration and invasion through the reversal of epithelial-mesenchymal transition. J Cell Sci. 2014;127(Pt 1):85-100. doi: 10.1242/jcs.132779.

12. Lippman ME, Rae JM, Chinnaiyan AM. An expression signature of estrogen-regulated genes predicts disease-free survival in tamoxifen-treated patients better than progesterone receptor status. Trans Am Clin Climatol Assoc. 2008;119:7790; discussion 90-2.

13. Martin LA, Dowsett M. BCL-2: a new therapeutic target in estrogen receptor-positive breast cancer? Cancer Cell. 2013;24(1):7-9. doi: 10.1016/j.ccr.2013.06.006.

14. McDermott MSJ, Canonici A, Ivers L, Browne BC, Madden SF, O'Brien NA, et al. Dual inhibition of IGF1R and ER enhances response to trastuzumab in HER2 positive breast cancer cells. Int J Oncol. 2017;50(6):2221-8.

15. de Groot S, Charehbili A, van Laarhoven HW, Mooyaart $\mathrm{AL}$, Dekker-Ensink NG, van de Ven S, et al. Insulin-like growth factor 1 receptor expression and IGF1R 3129G > T polymorphism are associated with response to neoadjuvant chemotherapy in breast cancer patients: results from the NEOZOTAC trial (BOOG 2010-01). Breast Cancer Res. 2016;18(1):3. doi: 10.1186/s13058-015-0663-3.

16. Bender LM, Nahta R. Her2 cross talk and therapeutic resistance in breast cancer. Front Biosci. 2008;13:3906-12. doi: $10.2741 / 2978$.

17. Harvey JM, Clark GM, Osborne CK, Allred DC. Estrogen Receptor Status by Immunohistochemistry Is Superior to the Ligand-Binding Assay for Predicting Response to Adjuvant Endocrine Therapy in Breast Cancer. J Clin Oncol. 1999;17(5):1474-81. doi: 10.1200/JCO.1999.17.5.1474.

18. Kelly MJ, Levin ER. Rapid actions of plasma membrane estrogen receptors. Trends Endocrinol Metab. 2001;12(4):1526. doi: 10.1016/s1043-2760(01)00377-0.

19. Schafer J, Bentrem D, Takei H, Gajdos C, Badve S, Jordan V. A mechanism of drug resistance to tamoxifen in breast cancer. J Steroid Biochem Mol Biol. 2002;83(1-5):75-83. doi: 10.1016/ s0960-0760(02)00251-0.

20. Elebro K, Borgquist S, Rosendahl AH, Markkula A, Simonsson M, Jirstrom K, et al. High Estrogen Receptor beta Expression Is Prognostic among Adjuvant Chemotherapy-Treated Patients-
Results from a Population-Based Breast Cancer Cohort. Clin Cancer Res. 2017;23(3):766-777. doi: 10.1158/1078-0432. CCR-16-1095.

21. Foukakis T, Bergh J. Prognostic and predictive factors in early, non-metastatic breast cancer. UpToDate website. 2016. Available from: https://www.uptodate.com/contents/ prognostic-and-predictive-factors-in-early-non-metastaticbreast-cancer.

22. Sample Size Calculator. Available from: https://www.calculator.net/sample-size-calculator.html?type $=1 \& \mathrm{cl}=95 \& \mathrm{ci}=10 \& \mathrm{p}$ $p=70 \& p s=\& x=70 \& y=13$.

23. Majidzadeh AK, Kaviani A, Esmaeili R, Farahmand L, Shojamoradi MH, Zare AA, et al. Iranian Breast Cancer BioBank: the activity and challenging issues. Cell Tissue Bank. 2013;14(1):11-20. doi: 10.1007/s10561-012-9293-5.

24. Majidzadeh AK, Esmaeili R, Abdoli N. TFRC and ACTB as the best reference genes to quantify Urokinase Plasminogen Activator in breast cancer. BMC Res Notes. 2011;4:215. doi: 10.1186/1756-0500-4-215.

25. Dunn SE, Ehrlich M, Sharp NJ, Reiss K, Solomon G, Hawkins $R$, et al. A dominant negative mutant of the insulin-like growth factor-I receptor inhibits the adhesion, invasion, and metastasis of breast cancer. Cancer Res. 1998;58(15):3353-61.

26. Khoury T, Sait S, Hwang H, Chandrasekhar R, Wilding G, Tan D, et al. Delay to formalin fixation effect on breast biomarkers. Mod Pathol. 2009;22(11):1457-67. doi: 10.1038/ modpathol.2009.117

27. Qiu J, Kulkarni S, Chandrasekhar R, Rees M, Hyde K, Wilding $\mathrm{G}$, et al. Effect of delayed formalin fixation on estrogen and progesterone receptors in breast cancer: a study of three different clones. Am J Clin Pathol. 2010;134(5):813-9. doi: 10.1309/AJCPVCX83JWMSBNO.

28. Cheang MC, Treaba DO, Speers $\mathrm{CH}$, Olivotto IA, Bajdik CD, Chia SK, et al. Immunohistochemical detection using the new rabbit monoclonal antibody SP1 of estrogen receptor in breast cancer is superior to mouse monoclonal antibody 1D5 in predicting survival. J Clin Oncol. 2006;24(36):5637-44. doi: 10.1200/JCO.2005.05.4155.

29. Khoury T, Yan L, Liu S, Bshara W. Oncotype DX RT-qPCR assay for ER and PR correlation with IHC: a study of 3 different clones. Appl Immunohistochem Mol Morphol. 2015;23(3):178-87. doi: 10.1097/PAI.0000000000000078.

30. LaTonia D, Taliaferro S, Elaine M. Silencing of IGF1R induces mesenchymal-to-epithelial transition and inhibits the metastatic properties of triple negative breast cancer cells. Proceedings of the 103rd Annual Meeting of the American Association for Cancer Research. Mar 31-Apr 4, 2012.

31. Rocha RL, Hilsenbeck SG, Jackson JG, VanDenBerg CL, Weng C, Lee AV, et al. Insulin-like growth factor binding protein-3 and insulin receptor substrate- 1 in breast cancer: correlation with clinical parameters and disease-free survival. Clin Cancer Res. 1997;3(1):103-9.

32. Turner BC, Haffty BG, Narayanan L, Yuan J, Havre PA, Gumbs $A A$, et al. Insulin-like growth factor-I receptor overexpression mediates cellular radioresistance and local breast cancer recurrence after lumpectomy and radiation. Cancer Res. 1997;57(15):3079-83.

33. Browne BC, Eustace AJ, Kennedy S, O'Brien NA, Pedersen K, McDermott MS, et al. Evaluation of IGF1R and phosphorylated IGF1R as targets in HER2-positive breast cancer cell lines and tumours. Breast Cancer Research and Treatment. 2012;136(3):717-27.

34. Yerushalmi R, Gelmon K, Leung S, Gao D, Cheang M, Pollak $M$, et al. Insulin-like growth factor receptor (IGF-1R) in breast cancer subtypes. Breast Cancer Res Treat. 2012;132(1):13142. doi: 10.1007/s10549-011-1529-8.

35. Gupta S, Joshi K, Wig J, Arora SK. The Implications of Higher TGF- $\beta 1$, IGF-II and IGF-1R mRNA expression in infiltrating 
breast carcinoma and their association with tumorigenesis and angiogenesis. Am J Biomed Sci. 2009;1(2):157-65.

36. Shimizu C, Hasegawa T, Tani Y, Takahashi F, Takeuchi M, Watanabe $\mathrm{T}$, et al. Expression of insulin-like growth factor 1 receptor in primary breast cancer: immunohistochemical analysis. Hum Pathol. 2004;35(12):1537-42. doi: 10.1016/j. humpath.2004.09.005.

37. Al Sarakbi W, Chong Y, Williams S, Sharma A, Mokbel K. The mRNA expression of IGF-1 and IGF-1R in human breast cancer: association with clinico-pathological parameters. J Carcinog. 2006;5:16. doi: 10.1186/1477-3163-5-16.

38. Ludovini V, Bellezza G, Pistola L, Bianconi F, Di Carlo L, Sidoni A, et al. High coexpression of both insulin-like growth factor receptor-1 (IGFR-1) and epidermal growth factor receptor (EGFR) is associated with shorter disease-free survival in resected non-small-cell lung cancer patients. Ann Oncol. 2009;20(5):842-9. doi: 10.1093/annonc/mdn727.

39. Lin YC, Chen CC, Cheng CJ, Yang RB. Domain and functional analysis of a novel breast tumor suppressor protein, SCUBE2. J Biol Chem. 2011;286(30):27039-47. doi: 10.1074/jbc. M111.244418.

40. Skrzypczak M, Lattrich C, Häring J, Schüler S, Ortmann O, Treeck O. Expression of SCUBE2 gene declines in high grade endometrial cancer and associates with expression of steroid hormone receptors and tumor suppressor PTEN. Gynecol Endocrinol. 2013;29(12):1031-5. doi: 10.3109/09513590.2013.829441.

41. Haldosen LA, Zhao C, Dahlman-Wright K. Estrogen receptor beta in breast cancer. Mol Cell Endocrinol. 2014;382(1):665672. doi: 10.1016/j.mce.2013.08.005.

42. Sapino A, Bosco M, Cassoni P, Castellano I, Arisio R, Cserni $\mathrm{G}$, et al. Estrogen receptor- $\beta$ is expressed in stromal cells of fibroadenoma and phyllodes tumors of the breast. Mod Pathol. 2006;19(4):599-606. doi: 10.1038/modpathol.3800574.

43. Miyoshi Y, Taguchi T, Gustafsson JÅ, Noguchi S. Clinicopathological Characteristics of Estrogen Receptor(3-positive Human Breast Cancers. Cancer Science. 2001;92(10):1057-61.

44. Zhang H, Zhang Z, Xuan L, Zheng S, Guo L, Zhan Q, et al. Evaluation of ER- $\alpha, E R-\beta 1$ and ER- $\beta 2$ expression and correlation with clinicopathologic factors in invasive luminal subtype breast cancers. Clin Transl Oncol. 2012;14(3):225-31. doi: 10.1007/s12094-012-0788-0.

45. Burges A, Brüning A, Dannenmann C, Blankenstein T, Jeschke $U$, Shabani N, et al. Prognostic significance of estrogen receptor alpha and beta expression in human serous carcinomas of the ovary. Arch Gynecol Obstet. 2010;281(3):511-7. doi: 10.1007/s00404-009-1185-y. 